\title{
SSTR1 and SSTR5 subtypes are the dominant forms of somatostatin receptor in neuroendocrine tumors
}

\author{
Hanna Pisarek ${ }^{1}$, Marek Pawlikowski ${ }^{1}$, Jolanta Kunert-Radek ${ }^{2}$, Robert Kubiak ${ }^{3}$, \\ Katarzyna Winczyk ${ }^{1}$
}

\author{
${ }^{1}$ Department of Neuroendocrinology, Medical University of Łódź, Poland \\ 2Department of Clinical Endocrinology, Medical University of Łódź, Poland \\ ${ }^{3}$ Department of Pathology of Tumors, Chair of Oncology, Medical University of Łódź, Poland
}

\begin{abstract}
The effectiveness of the long acting somatostatin analogues like octreotide and lanreotide depends on the expression of specific somatostatin receptors on the target cells. The immunohistochemical method performed on surgically removed tumors searches the expression of receptors at the level of receptor protein and gives us insight into receptor's cellular localization. The aim of study was to assess the presence of all the 5 subtypes of SSTR 1-5 (including 2A and 2B SSTR isoforms) in surgically treated human neuroendocrine tumors (NETs) to establish which receptor subtype is the dominant form of somatostatin receptor in particular tumor and thus to be able to predict which somatostatin analog will be effective in NETs treatment. 18 samples of neuroendocrine tumors (surgically excised tumors or biopsies) were immunostained with specific antibodies. Expression of SSTR was scored semiquantitatively. Only strong or moderate immunostaining was considered as positive reaction. The summarized expression pattern of SSTR in the investigated neuroendocrine tumors in our material was: SSTR 1 $>$ SSTR 5 $>$ SSTR 3 $>$ SSTR 2A $>$ SSTR 2B. The receptors were distributed mainly in the area of cells cytoplasm with a few specimens showing only membranous or mixed: membranous - cytoplasmic localization. The observed pattern suggests that apart from octreotide and lanreotide, newly synthesized multiligand analogs such as SOM 230, KE 108 or SSTR 1 and SSTR 5 selective analogs could be effective in NETs treatment.
\end{abstract}

Key words: somatostatin receptor subtypes, neuroendocrine tumors, immunohistochemistry.

\section{Introduction}

Somatostatin, especially its long acting analogues like octreotide and lanreotide play a very important role in diagnosis and treatment of patients with neuroendocrine tumors (NETs). Their effectiveness depends on the expression of specific somatostatin receptors (SSTR) on the target cells. Five subtypes of the SST receptor have been identified, i.e. SSTR 1-5 with two splicing variants $(2 \mathrm{~A}$ and $2 \mathrm{~B})$ of the type 2 receptor [for review see: 1]. Lately, the novel two variants of SSTR 5 (SSTR 5B and SSTR 5C) has been identified [2]. All of the subtypes belong to a family of 7 transmembrane domains linked with the $\mathrm{G}$ protein and are encoded by 5 genes present on separate chromosomes $[3,4]$. To make appriopriate diagnosis different tech-

Correspondence: H. Pisarek, Dept. of Neuroendocrinology, Medical University of Łódź, Sterling Str. 3, 91-425 Łódź, Poland; tel.: (+4842) 6324831, fax.: (+4842) 6365427, e-mail: h.pisarek@kardio-sterling.lodz.pl niques in vivo or ex vivo are being currently applied to detect SST receptors in human tumors. Octreoscan, receptor scintigraphy using indium labeled SST analogs: 111 In-pentetreotide $\{[111$ In-DTPA $]$ octreotide [5-8], 111 In-DOTA-lanreotide [9] or technetium labeled [99mTc-EDDA/HYNIC-Tate] octreotate $[10,11]$ have been proved most useful in vivo (Fig. 1). These methods allow to determine in vivo the tumor localization and size with good precision, however their effectiveness depends on the presence of subtype 2 SSTR in the tumor. The negative results obtained with octreoscan in pheochromocytoma or neuroendocrine tumors where the presence of SST receptors in the investigated tumors was demonstrated using the immunohistochemical method have been published $[12,13]$. There could be a considerable variation in SSTR expression between the different tumors types but also among tumors of the same type $[4,14]$. The diversity and coexistence of several somatostatin receptor subtypes in the same tumor unables an unequivocal prediction which somatostatin analog will 


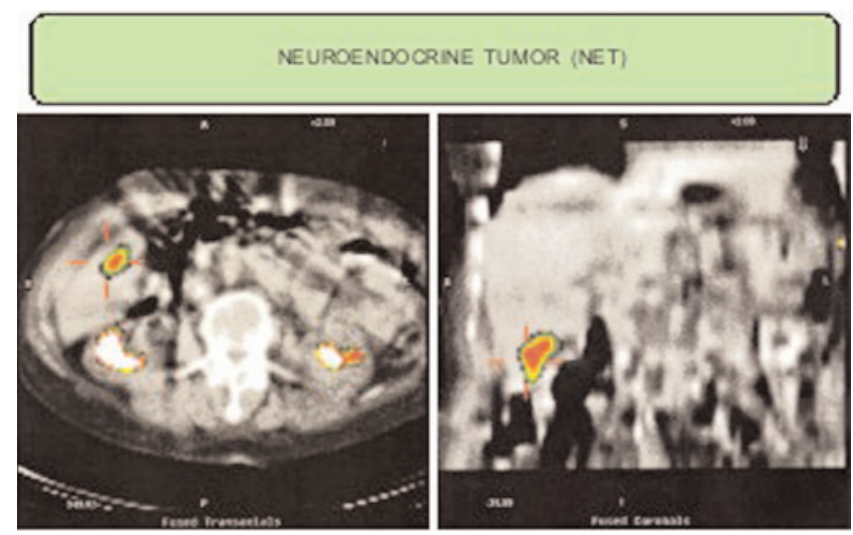

Fig. 1. SRS - high density of somatostatin receptors in carcinoid metastasis to the liver. Octreoscan - [99mTc-EDDA/HYNIC-Tate] octreotate - Green -yellow-orange colours of metastasis in the liver.

be effective in its treatment. The immunohistochemical (IHC) technique performed on paraffin embedded tissue specimens obtained from surgically removed tumors which are routinely used for histopathological examinations seems the best ex vivo in vitro method in detecting expression of SST receptors $[15,16]$. It searches the expression of receptors at the receptor protein level and gives us insight into receptor's cellular localization. Currently applied methods of molecular biology (PCR, RT-PCR, in situ hybridization -ISH, Northern-blotting) detect only the receptor mRNA, while giving no insight into receptor localization. The IHC method should be considered equally effective as diagnostic molecular biology methods or in vivo radiodiagnostic imaging. This method can be considered as having a high efficacy. In our previous studies we have investigated the immunohistochemical detection of SSTR expression in pituitary adenomas [17,18], adrenal gland tumors [19], thyroid tumors [20] using antibodies specific for a given receptor subtypes.

The aim of this study was to assess the presence of all the 5 subtypes of SSTR 1-5 (including 2A and 2B SSTR isoforms) in surgically treated human neuroendocrine tumors to establish which receptor subtype is the dominant form of somatostatin receptor in particular tumor and thus to predict which somatostatin analogs should be effective in NETs treatment.

\section{Materials and methods}

Tissue samples. Eighteen samples of neuroendocrine tumors (surgically excised tumors or biopsies) from 13 patients (11 women and 2 men, aged between 32-70 years, mean age 52.9) archivized in the Department of Neuroendocrinology were assessed. The material included 7 biopsy specimens of carcinoid metastases to the liver, 5 lung carcinoids, 1 intestinal carcinoid (contained primary focus and 3 metastases), 1 pancreatic neuroendocrine tumor and 1 thymic neuroendocrine tumor with ectopic secretion of ACTH , causing Cushing's syndrome.
Immunohistochemistry. For somatostatin receptor subtypes determination, $10 \%$ formalin or Bouin-Hollande fixed, dehydrated and paraffin embedded 4-5 $\mu \mathrm{m}$ sections were immunostained using commercially available rabbit polyclonal antisera raised against carboxyl-terminal fragments of specific human somatostatin receptor subtypes (GRAMSCH Laboratories, Schwabhausen, Germany): SSTR 1 (named SS-840 antibody, corresponding to amino acid sequence $377-391$ of the receptor's peptide chain), SSTR 2A (SS-800, specific for 355-369 sequence), SSTR 2B (SS-860, specific for 342-356 sequence), SSTR 3 (SS-850, specific for 381-395 sequence), SSTR 4 (SS-880, specific for 374-388 sequence) and SSTR 5 (SS-890, specific for 350-364 sequence). The immunohistochemical procedures were performed as previously described [21]. At first sections were dewaxed in xylene and rehydrated in ethanol. The antigen retrieval procedure performed prior to primary antibody incubation consist on microwave treatment in $0.01 \mathrm{M}$ citric acid buffer ( $\mathrm{pH}$ 6.0) two times for $5 \mathrm{~min}$ at $720 \mathrm{~W}$ and one time in $420 \mathrm{~W}$. To quench endogenous peroxidase activity sections were incubated in methanol containing $1.5 \% \mathrm{H}_{2} \mathrm{O}_{2}$ for $30 \mathrm{~min}$ at room temperature. The non-specific binding was blocked by preincubation with $3 \%$ normal goat serum for $30 \mathrm{~min}$ at room temperature. The working dilution of antibodies was 1: 1000 (diluted in $0.05 \mathrm{M}$ TRIS buffer, $\mathrm{pH} 7.6$ containing $2 \%$ goat serum). Following overnight incubation in $4^{\circ} \mathrm{C}$ in humidified chamber with primary antibodies, the tissues were treated with anti-rabbit IgG biotinylated goat antibody (1:800, DAKO, Denmark) and streptavidin complex (Strept ABC/HRP, DAKO, Denmark). The immunoreaction was visualized with 3.3'-diaminobenzidine (DAB, DAKO, Denmark) solution. For negative control the primary antibody was omitted and the normal goat serum was used. At least six sections per one tumor were examined. Because immunopositive tumors differed rather by intensity of staining and not by percentage of positive cells (which was usually near to $100 \%$ ), the examination concerned semiquantitative evaluation of the staining intensity and not of positive cells counts. The evaluation was done by two independent observers.

The immunoreactive intensity for specific receptor proteins was scored semiquantitatively using a descriptive scale as follows: strong staining $(+++)$, moderate staining $(++)$, weak staining $(+)$ and trace staining $(+/-)$. Only strong $(+++)$ or moderate $(++)$ staining was considered as positive of the given subtype of SSTR in the further descriptions. Subcellular distribution of SSTR subtypes membranous or cytoplasmic was also determined.

Ethical issues. This project received the approval of the Ethics Committee of Medical University of Łódź, no. RNN/97/06/KE.

\section{Results}

The expression of somatostatin receptor subtypes SSTR 1-5 was very differentiated both between the different tumors types and among tumors of the same type (carcinoids). Multiple SSTR subtypes were found to coexist in almost all of them. Strong and moderate positive immunostaining of SSTR 1 was observed in $11 / 17$ samples $(64.7 \%)$. In $6 / 17$ the intensity of reaction was variable (weak, weak to moderate, or even weak to strong). This subtype of SSTR was the dominant form among all of neuroendocrine tumors investigated (Tab.1). Somewhat lower score: 10/17 (58.8\%) cases was shown for SSTR 5. The scores 7/18 (38.9\%) and $8 / 17(47.1 \%)$ tumors were found in SSTR 2A and SSTR 3 respectively. Only 2 out of 15 (13.3\%) sam- 
Table 1. Summarized results concerning expression of somatostatin receptor subtypes in neuroendocrine tumors, determined by immunohistochemistry method (IHC).

\begin{tabular}{|c|c|c|c|c|c|c|}
\hline & SSTR 1 & SSTR 2A & SSTR 2B & SSTR 3 & SSTR 4 & SSTR 5 \\
\hline $\begin{array}{l}\text { Neuroendocrine tumors } \\
\text { (NET) }\end{array}$ & $\begin{array}{l}11 / 17 \\
64.7 \%\end{array}$ & $\begin{array}{c}7 / 18 \\
38.9 \%\end{array}$ & $\begin{array}{c}2 / 15 \\
13.3 \%\end{array}$ & $\begin{array}{c}8 / 17 \\
47.1 \%\end{array}$ & negative & $\begin{array}{l}10 / 17 \\
58.8 \%\end{array}$ \\
\hline
\end{tabular}

The immunoreactive intensity for specific receptor proteins was scored semiquantitatively using a descriptive scale as follows: strong staining (+++), moderate staining $(++)$, weak staining $(+)$ and trace staining $(+/-)$. Only strong $(+++)$ and moderate $(++)$ staining was considered as positive of the given subtype of SSTR.

ples demonstrated SSTR 2B immunopositivity of this intensity. None of the tumor representing SSTR 4 positive reaction was found. Female patient with carcinoid metastasis to the liver exhibited definitively strong intensity of staining of four subtypes (SSTR 1, 2A, 2B, 3 ) with trace reaction for SSTR 5. It is worth of interest that in several samples one could observed the extremely variable score from negative to strong or from weak to strong reaction in cell clusters in particular tumors. Summarized pattern of SSTR expression in the investigated neuroendocrine tumors was: SSTR $1>$ SSTR $5>$ SSTR $3>$ SSTR 2A $>$ SSTR 2B. The receptors immunopositivity was localized mainly in the area of cells cytoplasm with a few specimens showing only membranous or mixed: membranous cytoplasmic localization.

In the thymic neuroendocrine tumor only $30 \%$ of cells expressed SSTR 3 and SSTR 5 at the moderate intensity, remaining subtypes were at the weak level or negative. The strong immunoreaction in the vascular endothelium was also visible (Fig. 2). Pancreatic neuroendocrine cancer revealed SSTR 1 immunopositivity at the moderate to strong level. The other subtypes were weak or negative although we observed extreme score from negative to strong in some cell clusters (Fig. 3). In our series of neuroendocrine tumors the carcinoids and carcinoid metastases were the main group 16 all of the NETs samples. The same pattern of SSTR expression as in the all group was observed: SSTR 1 $>$ SSTR 5> SSTR 3>SSTR 2A $>$ SSTR 2B.

\section{Discussion}

Results of the present study demonstrate that somatostatin receptors are expressed in neuroendocrine tumors in a varied manner which is specific in each case. Multiple SSTR subtypes were found to coexist in each case of the investigated tumor with mixed distribution and various intensity. Our results did not confirm the earlier studies of other investigators where the SSTR 2 predominance is found in $>80 \%$ of endocrine pancreatic and digestive tract tumors [22,23]. Among the 20 carcinoid tumors investigated by Kimura et al. [24] all except 2 cases (90\%) showed moderate to strong immunoreactivity of SSTR 2A distributed mainly on the cell membrane and less intensively in the cytoplasm of the tumor cells. Carcinoid tumors examined by de Herder et al. [4] also showed the predominant expression of SSTR 2. Nasir et al. [25] have examined by immunohistochemistry 11 hepatic metastases of small intestinal carcinoids and have found SSTR 1 expression in $63 \%$, while SSTR 2 was expressed in $81 \%$, SSTR 3 in $72 \%$, SSTR 4 in $54 \%$ and SSTR 5 in $91 \%$. In the large majority of cases studied, the reaction was diffused in the cell cytoplasm although membranous localization was also noted. The authors explain this fact that their patients were on the octreotide treatment at the time of surgery. It is known that this somatostatin analog causes the receptor internalization and in consequence increases the SSTRpositivity in cells cytoplasm. In our group of patients we did not have any precise information about earlier therapy before surgery or biopsy, but certainly some of them were treated with octreotide. In the study of Kulaksiz et al. [26] immunohistochemical estimation of SSTR in carcinoids, revealed $37 \%$ of SSTR $1,86 \%$ of SSTR 2A, 71\% of SSTR 3 and $83 \%$ of SSTR 5 using the same specific antibodies as we did. Immunoreactivity for the receptor subtypes 1,3 and 5 was mainly localized in the cytoplasm while SSTR 2A was found exclusively on the cell membrane of all tumors were this type of receptor was expressed. These authors suggest, that the rapid targeting and integration of this receptor subtype into the cell membrane is responsible for inability of its detection in the cytoplasm. In our study, the lower score of positive SSTR expression is due to selection only strong or moderate staining as positive of the given subtype of SSTR in the descriptions. We used the antibodies of same kind and source and SSTR 2A (code SS-800) was find in $38.9 \%$, both in cytoplasm and cell membrane (Fig. 3, 4). Overall, SSTR 2A was more frequent than SSTR 2B. SSTR 1, 3, 5 also were characterized by a mixed distribution (Fig. 5,6). Consequently, in present study, we could not consider these antibodies (SS-840, SS-850, SS-890 respectively) as recognizing preferentially internalized receptors as Kulaksiz's group claims [26]. SSTR 2A antibody in our samples not only detected the integral membrane form of the receptor, but also the receptor protein located in the cytoplasm. Papotti et al. [27] reported their results of immunohistochemical studies in 15 gastrointestinal 

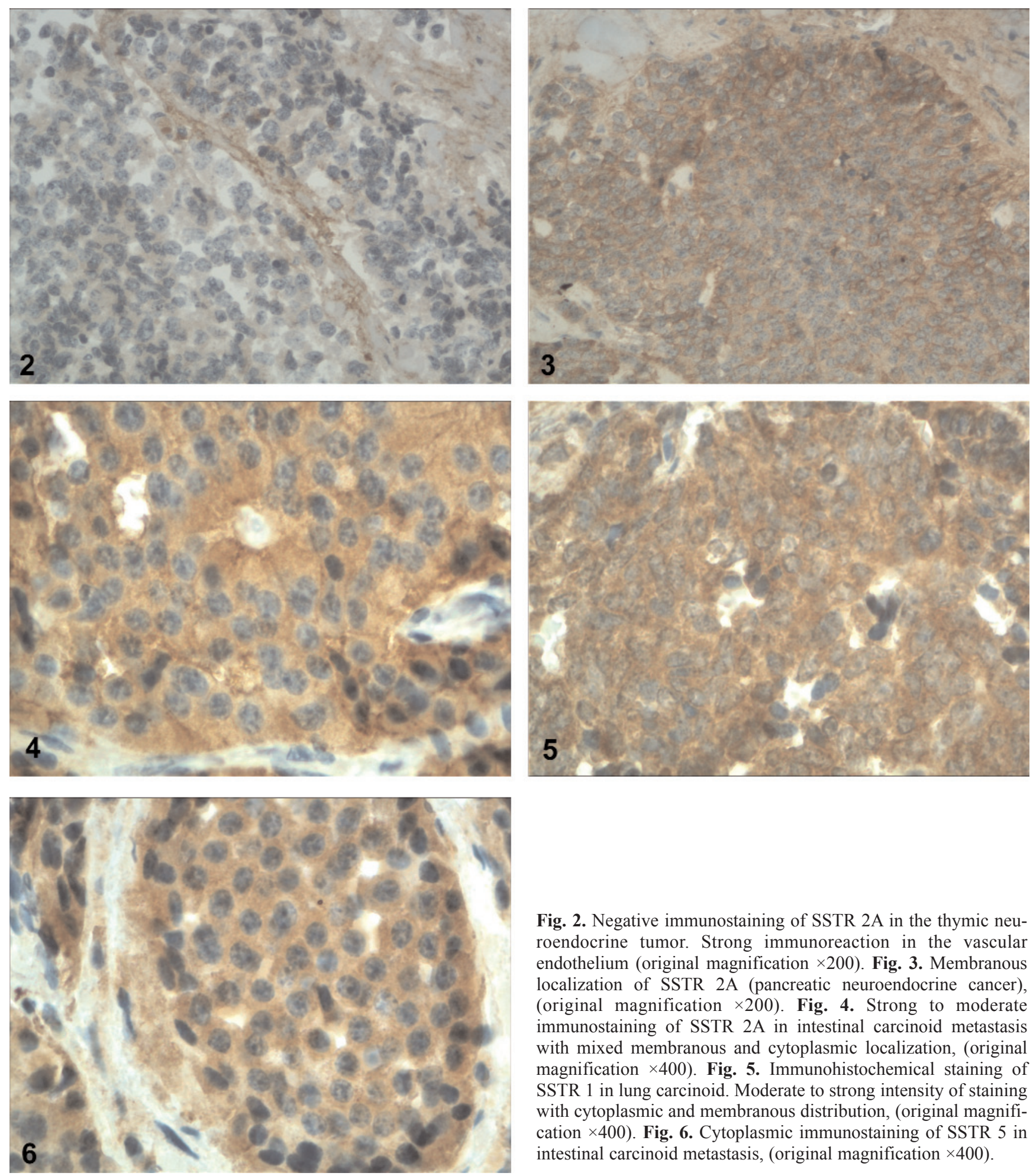

Fig. 2. Negative immunostaining of SSTR $2 A$ in the thymic neuroendocrine tumor. Strong immunoreaction in the vascular endothelium (original magnification $\times 200$ ). Fig. 3. Membranous localization of SSTR 2A (pancreatic neuroendocrine cancer), (original magnification $\times 200$ ). Fig. 4. Strong to moderate immunostaining of SSTR 2A in intestinal carcinoid metastasis with mixed membranous and cytoplasmic localization, (original magnification $\times 400$ ). Fig. 5. Immunohistochemical staining of SSTR 1 in lung carcinoid. Moderate to strong intensity of staining with cytoplasmic and membranous distribution, (original magnification $\times 400$ ). Fig. 6. Cytoplasmic immunostaining of SSTR 5 in intestinal carcinoid metastasis, (original magnification $\times 400$ ).

endocrine tumors, in which SSTR 2 immunoreactivity with the same antibody used by us (SS-800 from Gramsch Lab.) was found in 12/15 (80\%) of tumors with cell membrane localization, SSTR 3 in 9/15 (60\%) (the same antibody, too, from Gramsch Lab), SSTR 5 in 12/15 (80\%) with cell membrane and cytoplasmic reactivities. Either cytoplasmic or membra-

nous distribution of SSTR 2A was also reported by other authors using the same kind of antibodies in fixed, paraffin embedded samples (SS-840, SS-800, SS-850, SS-890) [18-20,28-30]. The studies of Jais et al. [31] using the molecular biology methods (PCR) showed the following expression of SSTR - mRNAs in 6 carcinoids investigated among 38 gastroen- 
teropancreatic tumors (GEP): $5 / 6(83 \%)$ of SSTR 1 , equally: 6/6 (100\%) of SSTR 2, SSTR 4 and SSTR 5, $1 / 6(17 \%)$ of SSTR 3. However, Reubi et al. [32] by in situ hybridization histochemistry detected SSTR 1 mRNA in 5/10 (50\%), SSTR 2 mRNA in 7/10 (70\%) and SSTR 3 mRNA in only 2/10 (20\%) of carcinoids. The results achieved by another group of researches [33] also reported on the different distribution of somatostatin receptor subtypes in 9 carcinoids tested by RT-PCR method: $44 \%$ of SSTR 1 mRNA, $67 \%$ of SSTR 2 mRNA, $33 \%$ of SSTR 4 mRNA and $56 \%$ of SSTR 5 mRNA. They did not detect the SSTR 3 mRNA in any of carcinoid cases tested. In our findings in turn there was no immunopositivity for subtype 4 of SST receptor in none of tested samples. Only Papotti's group [27] reported a poorly expressed SSTR 4 in pancreatic endocrine tumors and in $15.4 \%(2 / 13)$ of gastrointestinal endocrine tumors

Thus the divergence in results is evident and SSTR 1-5 expression pattern depends on the method of investigation used. The molecular biology method (mainly PCR ) is now more often used to investigate receptor expression. PCR gives results at the level of mRNA. However, even despite of gene expression it could occurs the posttranslational modification of SSTR without protein synthesis. Thus, mRNA detection alone is not sufficient to confirm the presence of receptor protein which is the molecular target for somatostatin and its analogs [16,34]. In this method we could not obtain also the data concerning localization of receptor at the cellular level and thus to presume the receptor activity. Some authors concern as immunopositive and active only membrane located SSTR 2 but for SSTR 3 and SSTR 5 only its cytoplasmic localization $[35,36]$ in neuroendocrine tumors.

\section{Conclusions}

To summarize, somatostatin receptors are expressed in neuroendocrine tumors in a varied manner which is specific in each case. The summarized pattern of SSTR expression in the investigated neuroendocrine tumors in our material was: SSTR 1> SSTR 5> SSTR 3> SSTR 2A $>$ SSTR 2B. The observed pattern suggests that apart from SSTR 2 and SSTR 5- preferring octreotide and lanreotide, newly synthesized multiligand analogs such as SOM 230 -pasireotide, KE 108 or SSTR 1 and SSTR 5 selective analogs could be effective in NETs treatment. The receptors were distributed mainly in the area of cells cytoplasm with a few specimens showing only membranous or mixed, membranous - cytoplasmic localization.

Acknowledgements: The project was supported financially by Medical University of Łódź, No 503-5084-1. The author would like to thanks dr Hanna Ławnicka for her skillful informatic help.
Conflict of Interest Statement: The authors declare that they have no competing interests.

\section{References}

[ 1] Mełeń-Mucha G, Mucha S. Somatostatin Receptors: Distribution in Normal Tissues and Transduction Mechanisms. In: Somatostatin Analogs in Diagnostics and Therapy. Edited by Marek Pawlikowski, Landes Bioscience. 2007, pp. 7-20.

[2] Cordoba-Chacon J, Luque RM, Gahete MD et al. Identification and molecular characterization of new somatostatin receptor subtype 5 truncated isoforms in rodents. Endocr Abstracts. 2008;16: P463.

[3] Reisine T, Bell G. Molecular Biology of Somatostatin Receptors. Endocr Rev. 1995; 16:427-442.

[ 4] de Herder WW, Hofland LJ, Van der Lely AJ et al. Somastostatin Receptors in gastroenteropancreatic neuroendocrine tumours. Endocr Rel Cancer. 2003;10:451-458.

[5] Krenning EP, Kwekkeboom DJ, Bakker WH et al. Somatostatin receptor scintigraphy with [ 111In- DTPA-D-Phe1]- and [123I-Tyr3]-octreotide: the Rotterdam experience with more than 1000 patients. Eur J Nucl Med. 1993;20:716-731.

[ 6] McCarthy KE, Woltering EA, Anthony LB. In situ radiotherapy with 111In-pentetreotide: state of the art and perspectives. Q J Nucl Med. 2000;44:88-95.

[ 7] Oberg K. Carcinoid tumors: molecular genetics, tumor biology, and update of diagnosis and treatment. Curr Opin Oncol. 2002;14:38-45.

[ 8] de Herder WW, Kwekkeboom DJ, Feelders RA et al. Somatostatin receptor imaging for neuroendocrine tumors. Pituitary. 2006;9:243-248.

[9] Virgolini I, Patri P, Novotny C et al. Comparative somatostatin receptor scintigraphy using in-111-DOTA-lanreotide and in-111-DOTA-Tyr3-octreotide versus F-18-FDG-PET for evaluation of somatostatin receptor-mediated radionuclide therapy. Ann Oncol. 2000;12(Suppl.2):S41-S45.

[10] Kamiński G, Szaluś N, Pietrzykowski J et al. Somatostatin receptor scintigraphy with $99 \mathrm{mTc}-\mathrm{HYNIC}$-TATE and computed tomography in accurate visualisation of neuroendocrine tumours (NETS). Pol J Endocrinol. 2005;56:S11-4.

[11] Hubalewska-Dydejczyk A, Szybiński P, Fross-Baron K et al. (99m)Tc-EDDA/HYNIC-octreotate- a new radiotracer for detection and staging of NET: a case of metastatic duodenal carcinoid. Nucl Med Rev Cent East Eur. 2005;8:155-156.

[12] Zatelli MC, Piccin D, Bondanelli $\mathrm{M}$ et al. An in vivo OctreoScan-negative adrenal pheochromocytoma expresses somatostatin receptors and responds to somatostatin analogs treatment in vitro. Horm Metab Res.2003;35:349-54.

[13] Kunert-Radek J, Biernacka A, Dobaczewski M, Pisarek H, Pawlikowski M, Kuśmierek J. Immunohistochemistry and scintigraphy of somatostatin receptors in patients with neuroendocrine tumors. ENEA 2006, 12th Meeting of the European Neuroendocrine Association. Hormones. Int $J$ Endocrinol Metab. 2006;5:Suppl.1:P181.

[14] Hofland LJ, Lamberts SWJ. Somatostatin receptor subtype expression in human tumors. Ann Oncol. 2001;12:(Suppl. 2): S31-S36.

[15] Pawlikowski M. The incidence of somatostatin receptors in human neoplasms in the light of ex vivo-in vitro studies. Pol J Endocrinol. 2006;57:238-243.

[16] Pawlikowski M. Somatostatin Receptors in Human TumorsIn Vitro Studies. In: Somatostatin Analogs in Diagnostics and Therapy. Edited by Marek Pawlikowski, Landes Bioscience. 2007, pp. 39-46.

[17] Pawlikowski M, Pisarek H, Kunert-Radek J, Radek A. Immunohistochemical Detection of Somatostatin Receptor Subtypes in "Clinically Nonfunctioning" Pituitary Adenomas. 
Endocrine Pathol. 2003;14:231-238.

[18] Pisarek H, Pawlikowski M, Kunert-Radek J, Radek M. Expression of somatostatin receptor subtypes in human pituitary adenomas - immunohistochemical studies. Pol $J$ Endocrinol, 2009;4:240-251.

[19] Pisarek H, Stępień T, Kubiak R, Pawlikowski M. Somatostatin receptors in human adrenal gland tumors - immunohistochemical study. Folia Histochem Cytobiol. 2008;46:251-257.

[20] Pisarek H, Stępień T, Kubiak R, Borkowska E, Pawlikowski M. Expression of somatostatin receptor subtypes in human thyroid tumors: the immunohistochemical and molecular biology (RT-PCR) investigation. Thyroid Res. 2009;2:1.

[21] Schulz S, Schulz St, Schmitt J et al. Immunocytochemical Detection of Somatostatin Receptors sst1, sst2A and sst3 in Paraffin - embedded Breast Cancer Tissue Using Subtype specific Antibodies. Clin Cancer Res. 1998;4:2047-2052.

[22] Oberg K, Kvols L, Caplin M et al. Consensus report of the use of somatostatin analogs for the management of neuroendocrine tumors of the gastroenteropancreatic system. Ann Oncol. 2004;15:966-973.

[23] Reubi JC, Waser B, Schaer JC, Laissue JA. Somatostatin receptor sst1-sst5 expression in normal and neoplastic human tissues using receptor autoradiography with subtype-selective ligands. Eur J Nucl Med. 2001;28:836-846.

[24] Kimura N, Pilichowska M, Date F, Kimura I, Schindler M. Immunohistochemical Expression of Somatostatin Type 2A Receptor in Neuroendocrine Tumors. Clin Cancer Res. 1999;5:3483-3487.

[25] Nasir A, Stridsberg M, Strosberg J et al. Somatostatin Receptor Profiling in Hepatic Metastases From Small Intestinal and Pancreatic Neuroendocrine Neoplasms: Immunohistochemical Approach With Potential Clinical Utility. Cancer Control. 2006;13:52-60.

[26] Kulaksiz H, Eissele R, Rossler D et al. Identification of somatostatin receptors subtypes $1,2 \mathrm{~A}, 3$ and 5 in neuroendocrine tumours with subtype specific antibodies. Gut. 2002;50:52-60

[27] Papotti M, Bongiovanni M, Volante M, Landolfini EA, Helboe L, Schindler M. Expression of somatostatin receptor types 1-5 in 81 cases of gastrointestinal and pancreatic endocrine tumors: a correlative immunohistochemical and reverse-transcriptase polymerase chain reaction analysis. Virchows Arch. 2002;440:461-475.

[28] Mundschenk J, Unger N, Schulz S, et al. Somatostatin Receptor Subtypes in Human Pheochromocytoma: Subcellular Expression Pattern and Functional Relevance for Octreotide Scintigraphy. J Clin Endocrinol Metab. 2003;88:5150- 5157.

[29] Schulz S, Schmitt J, Quednow C et al., Immunohistochemical Detection of Somatostatin Receptors in Human Ovarian Tumors. Gynecol Oncol. 2002:84:235-240.

[30] Taniyama Y, Suzuki T, Mikami Y, Moryia T, Satomi S, Sasano H. Systemic distribution of somatatostatin receptor subtypes in human: an immunohistochemical study. Endocrine J. 2005; 52:605-611.

[31] Jais P, Terris B, Ruszniewski P, LeRomancer M, Reyl-Desmars F. Somatostatin receptor subtype gene expression in human endocrine gastroentero-pancreatic tumours. Eur J Clin Invest. 1997;27:639-644.

[32] Reubi JC, Schaer JC, Waser B, Mengod G. Expression and localization of somatostatin receptor SSTR 1, SSTR 2 and SSTR 3 messenger RNAs in pituitary human tumors using in situ hybridization. Cancer Res. 1994;54:3455-3459.

[33] Wulbrand U, Wied M, Zofel P, Goke B, Arnold R, Fehmann $\mathrm{H}$. Growth factor receptor expression in human gastroenteropancreatic neuroendocrine tumors. Eur $J$ Clin Invest. 1998;28:1038-1049.

[34] Reubi JC, Waser B, Liu Q et al. Subcellular Distribution of Somatostatin sst2A Receptors in Human Tumors of the Nervous and Neuroendocrine Systems: Membranous Versus Intracellular Location. J Clin Endocrinol Metab. 2000;85: 3882-3891.

[35] Volante M, Brizzi MP, Faggiano A et al. Somatostatin receptor type 2A immunohistochemistry in neuroendocrine tumors: a proposal of scoring system correlated with somatostatin receptor scintigraphy. Mod Pathol. 2007;20:1172-1182.

[36] Faggiano A, Volante M, Brizzi MP et al. Somatostatin receptor immunohistochemistry in neuroendocrine tumors: a proposal of scoring system for clinical characterization and therapy selection. Endocr Abstracts. 2007;14:P168.

Submitted: 18 September, 2009 Accepted after reviews: 11 January, 2010 